\title{
Um Certo Olbar de Fátima Bettencourt sobre Cabo Verde
}

\author{
Simone Caputo Gomes \\ Universidade de São Paulo
}

RESUMO: A PARTIR DO LIVRO DE CRÔNICAS INTITULADO UM CERTO OLHAR: CRÔNICAS, DE FÁTIMA BETTENCOURT, TRAÇAM-SE AS LINHAS DE FORÇA DA POÉTICA DA AUTORA.

ABSTRACT: BASED ON THE CHRONICLE BOOK ENTITLED UM CERTO OLHAR: CRÔNICAS, BY FÁTIMA BETTENCOURT, SOME LINES OF FORCE OF THE AUTHOR'S POETIC ARE TRACED.

PALAVRAS-CHAVE: LITERATURA CABOVERDIANA, CRÔNICA, FÁTIMA BETTENCOURT. KEY-WORDS: CAPE VERDIAN LITERATURE, CHRONICLE, FÁTIMA BETTENCOURT. 
crônica, portanto, é uma tenda de cigano enquanto consciência da nossa transitoriedade; no entanto é casa _ e bem sólida até _ quando reunida em livro, onde se percebe com maior nitidez a busca de coerência no traçado da vida, a fim de torná-la mais gratificante e, somente assim, mais perene".

Jorge de Sá

Os ecos saudosos das palavras de um dos mais assíduos estudiosos da crônica no Brasil resumem a impressão que nos causa, de início, Um certo olhar: crônicas, de Fátima Bettencourt (2001), de que tomamos conhecimento pelas cópias dos originais enviados gentilmente pela autora, antes da edição em livro.

Professora, jornalista, locutora, produtora, apresentadora de programas radiofônicos, contista (Semear em pó, 1994), Fátima, natural de Santo Antão (1938), vem reunir sua colaboração regular na imprensa, de 1992 a 1997, nesta coletânea de crônicas.

Sabemos que o jornal e a revista conferem à cronista a missão de colocar a vida no exíguo espaço da narrativa curta: a crônica herda do periódico a precariedade e a efemeridade. Ao eternizar suas crônicas em livro, a autora seleciona textos, atribui-lhes uma seqüência cronológica e temática capaz de mostrar ao leitor um mosaico antes fragmentado nas páginas dos periódicos. A construção dos tipos (retratos) e a focalização dos acontecimentos compõem o painel de um tempo (Cronos) e de uma sociedade. Assim a "tenda" se torna "casa".

Reunindo em volume suas crônicas publicadas em alguns dos principais periódicos de Cabo Verde, como A Semana, Novo Jornal de Cabo Verde, Horizonte (jornais), Artiletra e Cultura (revistas), Fátima Bettencourt vai resgatar o valor sociológico da crônica na construção do painel da sociedade crioula dos anos noventa, dando relevo ao pitoresco, ao acidental, ao banal, ao aparentemente irrisório do seu quotidiano.

$\mathrm{Na}$ simplicidade reside a beleza da sua crônica.

"Afinal o que me inspira é o nosso quotidiano de vivências simples e não os momentos de solene intimismo em que, sozinha, olhando a folha em branco, lucubro que nada vale a pena" (crônica "Angústia", 1992).

No exercício da crônica - esta "conversa fiada" com o leitor, como a qualificava Vinícius de Moraes - o prosador do quotidiano busca fundo na sua 
imaginação um fato qualquer, de preferência colhido no noticiário matutino ou da véspera, em que possa com suas artimanhas injetar sangue novo. Na prosa do dia-a-dia, misto de jornalismo e literatura, a busca do pitoresco permite ao cronista capturar o lado engraçado das coisas, fazendo do riso ou da ironia estratégias para examinar determinadas contradições da sociedade. O humor possibilita a recuperação da capacidade crítica, enquanto o leitor se diverte.

No prefácio ("Nota brevíssima, provavelmente dispensável"), a cronista adverte: "o riso, algum, que logrei descobrir no fundo da indignação que é, na maior parte dos casos, a alavanca da pena que humildemente venho manuseando" (BETTENCOURT, 2001, p. 13).

Um certo olhar de Fátima Bettencourt, desde o título, nos dá a medida de um painel que se estrutura a partir de um ângulo, agudo: a cronista não é "mulher de medos" (Ibidem, p. 173). A partir de um olhar crítico ou de uma "leitura em diagonal" (Ibidem, p. 179), vai pintando retratos e cenas com palavras, desvendando a gênese de sua coluna (Rostos e palavras) no jornal A Semana e do seu próprio texto literário:

“(...) o impulso que leva as coisas a se corporizarem em palavra escrita, quer se escrevam páginas imortais ou levíssimas crônicas. (...) E porque, afinal, são as palavras que se colocam, umas com as outras, as responsáveis por tudo, ela está no título genérico da coluna. É com elas que ganhamos o pão nosso de dia-sim-dia-não, com elas reclamamos porque não é de dia-sim-dia-sim, com elas vivemos, sofremos, lutamos, nos comunicamos, amamos, odiamos" (...).

Quanto aos rostos, eu sei que o leitor está à espera de uma boa justificação, uma história bem contada, nada, suponho, como aquilo que tenho para dizer.

O rosto é tudo, são os seres humanos, os que conheço ou sei de ouvido ou imaginação, são os bons e os maus, os públicos e os anónimos, os transparentes e os ocultos, os da miséria e os da bonança, os da vingança e os do perdão, os da coragem e os do desânimo, os que vivem apenas nas lembranças e na saudade e os que, nebulosos, já caem no esquecimento. Quantos rostos guardamos numa vida em estranha e progressiva colecção?(...) colecções únicas, preciosas e, por vezes, muito perturbadoras" ("Angústia”, grifos de Fátima).

De fatos e feitos da vida, emocionalmente despertados pela concentração, pode também surgir a crônica, deflagrando num instante uma visão da essên- 
cia, revestida do cômico ou da tragicidade. Para Rubem Braga, como aqui, a verdade da crônica é o instante: os pequenos momentos permitem entrever a condição humana. É fundamental que o cronista se defina num tempo e num espaço, compondo uma cronologia esclarecedora da sua relação com os seres e objetos.

Além disto, a crônica precisa atingir o máximo de matizes com o mínimo de elementos, em virtude de sua economia estrutural, pelo limite de espaço que ocupa no periódico.

O trabalho de Fátima Bettencourt neste Um certo olhar marca, a par da busca constante do resgate da tradição (já evidenciada no seu conto premiado, "Vovô", que dá início ao volume Semear em pô), o tempo e o espaço social em que se insere. A coletânea de crônicas estrutura-se de forma circular, caminhando das "Origens" às raízes, em "Avô, tataravô e outros que não sei nomear" - a última crônica do livro, que cita a primeira. Nos dois textos a cronista reflete sobre questões de identidade e de assunção das raízes negras com humor cáustico, evidenciando aquele seu "olhar de um modo especial" para um quadro ou situação. Na crônica "Origens” reflete Fátima:

"Temos, via de regra, orgulho excessivo na nossa costela lusitana, francesa, italiana, inglesa e outras. As restantes costelas, todas vindas directamente do Continente Africano, ficam numa nebulosa indefinida, confinada a uma silêncio total, ninguém delas toma conhecimento, o acordo é tácito, não há denúncias, pesquisas muito menos, e dos avós negros nem novas nem notícias. (...) Bem que podíamos assumir as duas raízes: a negra e a europeia. Mas não, ninguém procura, ninguém quer saber" (Ibidem, pp. 15-16).

E acrescenta, na crônica "Avô, tataravô e outros que não sei nomear":

"Sempre admirei um escritor afro-americano que teve a coragem de partir em busca das suas raízes negras e onde todos esperavam um enorme insucesso, para espanto de todos, foi o contrário. O livro, intitulado RAÍZES, que descreve a homérica tarefa, imortalizou o autor e se transformou em estandarte dos negros de todo o mundo.(...) Nestas nossas ilhas achadas desertas e durante muitos anos interposto do comércio escravo, nas mãos de traficantes, negreiros e bandoleiros, proliferou uma mestiçagem desenfreada, mas registo que é bom, muito pouco. 
Se nem dos avós brancos damos conta certa, que será dos negros?” (Ibidem, pp. 591-592).

O tema das raízes identitárias será trabalhado em profundidade, a partir do mito da origem do arquipélago de Cabo Verde e do homem cabo-verdiano, nas crônicas "Acaso", de que adiante destacaremos um fragmento, e "O uso da palavra" (p. 168):

"Não me canso de meditar na estória, certamente inventada por algum crioulo folgazão e sparajóde, que explica o nascimento das Ilhas do nosso Arquipélago: estaria o Criador em pleno acto de feitura do mundo quando, vencido pelo cansaço e pelo sono, teria deixado cair a pena com que se entretinha esboçando o que viria a ser montes, árvores, rios, elefantes, baleias, porcos e galinhas. Da caneta descuidada saltaram alguns pingos de tinta que surpreenderam o Pai Celeste, ao despertar, pois julgava ter retocado tudo havia já um bom tempo. Sorrindo porém com ironia e um pouco de malícia murmurou para os divinos botões: 'Deixa lá, não me lembro de ter colocado aí esses pontinhos mas se estão ali, vão ficar. Serão as ilhas de Cabo Verde’. (...) Ele como ser supremo é que não podia jamais dar o braço a torcer e admitir que os tais pingos espalhados no mar eram obra do acaso.

Do acaso nascemos, por acaso fomos achados e não me admiraria nada que fosse também obra do acaso o vovô branco ter botado o olho na vovó negra para gerar o mestiço mais inquieto e insatisfeito, vaidoso e ingênuo que habita este planeta" (Ibidem, p. 327).

A Cidade Velha, com suas "vetustas pedras" a simbolizar o patrimônio (crioulo e da Humanidade), é retratada na crônica "Legados" (pp. 195-197).

Outro velho, o embondeiro, em texto dedicado ao Pai (o "mais-velho" da autora) vai fazer parte da paisagem:

"Sem qualquer preocupação ecológica vou hoje contar-vos a história de uma árvore.

O Velho Embondeiro caiu. Está por terra, inerte, mas curiosamente imponente mesmo na horizontal. Há nele uma velada alegria em beijar o chão, suporte de longa data das suas inúmeras raízes que penetravam fundo aquela terra amada. 
Velha árvore ressequida e cansada, dos seus ramos se desprende ainda uma força e energia que é, apesar de tudo, vida. O seu tronco enrugado conta estórias mil, cada anel um sonho mais no galgar da humanidade. Em seus ramos múltiplos e emaranhados, pardais e passarinhos trouxeram ao mundo gerações de filhotes em ninhos construídos com amor" (Ibidem, p. 305).

As raízes literárias cabo-verdianas serão também trazidas à cena, num diálogo da contemporaneidade com a geração fundadora da Claridade, representada pelas obras Arquipélago e Ambiente, de Jorge Barbosa. A crônica "Ainda o ambiente" tem como referência a seca, os riscos de desertificação em Cabo Verde, a cabra (animal simbólico da resistência cabo-verdiana em meio ao drama climático), o heroísmo épico dos habitantes das ilhas a tentar deter a destruição da flora e da fauna. O vocábulo "ainda" sugere a permanência do espaço inóspito, desde a focalização de Barbosa até nossos dias:

"Outro dia, na abertura de um Seminário, fiquei surpreendida com algumas coisas que vi e ouvi sobre a nossa fauna e flora e mais ainda com os riscos de desertificação progressiva e irreversível.

_ Sabes, minha filha, esta terra não tem futuro. Daqui a quatrocentos anos estará totalmente coberta de areia. (...)

De então para cá, de cada vez que vejo um areal galopando, lembro-me com um frio na espinha, das previsões da minha amiga. (...) Mas logo o meu espírito se invade de esperança quando olho para o outro lado e vejo milhares de árvores que as mãos dos que ficaram têm plantado nestas encostas antes completamente escalavradas. (...)

Quando falamos em desertificação em Cabo Verde vem logo à baila o papel destruidor da cabra que, sem ser esquisita, degusta com o mesmo apetite voraz uma erva, um jornal, uma partitura e até mesmo um edital de casamento.

Nessas alturas todos parecem esquecer que sem a cabra provavelmente não teríamos sobrevivido. Qual o ser vivente destas ilhas que simboliza melhor que ela a perseverança, a teimosia e a sobrevivência? Não podemos é deixá-la por aí à toa. Se foi possível domesticá-la no passado remoto, é agora urgente racionalizar o seu espaço. 
Conservar a natureza sim, mas conservar também a cabra. Seu perfil altivo no cimo do cutelo nos lembrará sempre que estamos aqui para desafiar a natureza agreste e continuar" (Ibidem, pp. 39-41).

A paisagem física devastada e a paisagem humana inquebrantável serão enfatizadas nas crônicas "Interrogações" e "Estranhos casos":

"Pelo menos nos dias das gerações presentes, mais velhas ou mais novas, sempre nos habituámos aos montes escalavrados, à chuva mínima, mais no mar do que na terra seca, às cargas de lenha nas cabeças das mulheres ou no lombo das alimárias" (Ibidem. "Interrogações", p. 45).

"Açoitados pelo sol inclemente e por devastadora seca, os nossos campos nada têm para mostrar a quem passa a não ser pura desolação. As alimárias comem restos ressequidos de mato bravo, mulheres e crianças andam quilômetros para transportar a pouquíssima água que conseguem arranjar, não se entende muito bem do que estão vivendo as populações dos nossos campos.

Que nos resta então, a nós que vamos até Assomada na esperança duma brisa menos escaldante e duma ar menos poluído? Olhar a paisagem? Mas que paisagem se a maioria das árvores está reduzida a gravetos quebradiços?” (Ibidem. "Estranhos casos", p. 503).

Da paisagem humana destacam-se mulheres, crianças e velhos, abandonados (p.94).

A mulher anônima ou a Vênus cabo-verdiana, como a denomino, é uma personagem fundamental aos textos de Fátima: seja a menina precocemente grávida na crônica "Metáforas e floreados" (p. 97); seja o "novo perigo que espreita a Cidade Maravilhosa (...) as bolseiras" (p. 220) ou rabidantes caboverdianas; ou "as mulheres que vibram nas telas de Kiki Lima (...) com um alguidar de peixe ou um tabuleiro de bananas à cabeça” (p. 235), que podem ser trocados por uma enxada se uma água milagrosa vier. Enfim, a "Mulher sem rosto" (p. 417) é homenageada como representante "de milhares de mulheres espalhadas pelas nossas ilhas, mulheres cuja luta por um pouco de dignidade só acaba com a morte" (p. 419).

A OMCV (Organização das Mulheres de Cabo Verde) buscará amparo e apoio para essas mulheres do povo e Fátima Bettencourt citará várias vezes a 
organização (pp. 340, 349, 390), ressaltando a sua importância na promoção de ações que melhorem as condições de vida da mulher em Cabo Verde e especialmente das mulheres chefes-de-família.

A "Mulher de Sucesso", alegoria da visibilidade maior do papel da mulher na sociedade cabo-verdiana, será a protagonista da crônica "Vocações":

"Essa história me ocorreu ao deparar há dias com um Mulher de Sucesso, melhor dizendo, subindo um a um os degraus que a levarão lá. Eu nunca reparava nela como tal, mas de repente senti os passos firmes, olhei e vi a leve inclinação da cabeça acompanhada dum estranho inteiriçamento da nuca, até o ângulo do nariz com a testa estava diferente. Deu umas voltas pela sala, sorriu para uns poucos, meteu e tirou papéis da grande pasta de executiva, segredou cochichos ao ouvido dum chefe, fez pequenas intervenções avisando que era apenas para precisar e saiu da sala acompanhada pelos olhos de todos e deixando atrás de si o perfume inconfundível do sucesso" (Ibidem, p. 267).

As mulheres sem nome que, no seu labor cotidiano, constroem o país, transmitem e preservam a cultura têm seus perfis delineados pelo texto de Fátima:

"Mulheres jovens, maduras, idosas, cada uma o seu encanto, a sua força. (...) Uma mulata explode na dança de um vestido curto amarelo gema de ovo, a saia esvoaça no compasso do ritmo, revela no saracoteio o corpo bonito sugerindo o que não mostra.

Mulheres vendedeiras complementam e rentabilizam o suor do seu homem. As da terra e as do mar. (...)

Em todas a mesma dignidade e a certeza de pertencerem a um chão que fez delas' guerrilheiras' da vida de onde sacam a pulso a determinação e a vontade de vencer mas também a alegria e a musicalidade de todos os gestos e a sabedoria secular que lá de longe se vem acumulando até hoje” (Ibidem, p. 236).

A ilha (a mátria) e a cidade são percebidas como femininas, dentro da perspectiva de centramento do olhar na visão da mulher: "Isabel Barreno diz que São Vicente é uma ilha feminina. Eu diria que feminina e ciumenta é a cidade do Mindelo" (Ibidem, p. 229). 
Nas crônicas de Fátima Bettencourt, com base no destaque dado à mulher comum como personagem, o cabo-verdiano anônimo, por extensão, é retratado no seu cotidiano, com o tempero da tragicidade ou do humor. Vejamos a crônica "Entre porcos e balaios":

“Mas se pensarem um pouco na vidinha do 'povão' que não tem emprego fixo nem preparação e capital para desenvolver qualquer tipo de actividade privada, aí vão concordar comigo que 'Entre porcos e balaios' pode muito bem ser a síntese da nossa vidinha na busca difícil da cachupa diária, a luta secular 'dessa outra gente aí, fraca e miúda' no dizer de Saramago.

O Dr. Baltasar com muita graça e fruto do seu agudo sentido de observação que Caixa Econômica de pobre em Cabo Verde é o porco. Mas como? (...) põe um porquinho num chiqueiro, engorda-o como Deus quer, quase sempre dos restos que vai buscar às casas remediadas e abastadas (...). Aí quando o porquinho vira porco taludo sai a dona pelas casas das comadres todas que conhece, coloca uma perna aqui, 2 quilos de costelas ali e assim por diante até reunir o número sufuciente de compromissos de venda que permita apenas deixar algum para temperar a cachupa da casa. Só então, e não antes, mata o animal. (...)

Com esse dinheiro parte rápida para a compra de um bom leitão que vai ocupar imediatamente o lugar do anterior. Sobeja um bom quinhão com o qual cava os alicerces de uma casinha. Com o próximo manda fazer uns blocos, depois virão pedras, areia e cimento e dali a pouco deixa de pagar renda porque já tem casa própria. Tudo isso com inúmeras vantagens: não precisou de fiador, não pagou juros, deu aos vizinhos a oportunidade de the prestar solidariedade, teve a alegria de construir com suas próprias mãos. (...)

Penso muitas vezes nessa teoria do Dr. Baltasar, nascida da observação da vivência do pobre das nossas ilhas e creio estar ali a explicação para a nossa teimosia em existir.

(...) nas fomes que assolaram o Arquipélago no passado, houve gente que sobreviveu a comer lagartixas" (Ibidem, pp. 163-166).

O trecho é importantíssimo, por vários motivos: em primeiro lugar, o Dr. Baltasar é o Ti-Baltas ou o Mestre Baltasar, estudioso incansável do dialeto crioulo de Santiago, como a crônica refere (p. 164) e escritor que, na ficção e na poesia revelou, no bojo da proposta da Claridade de "mergulhar as raízes 
no chão crioulo", a terra e as gentes crioulas, semeadura fértil que as gerações foram colhendo, replantando, cuidando. Fátima Bettencourt é uma das escritoras que reinventa, dia após dia, a lição de Ti-Baltas, que remonta às origens da literatura cabo-verdiana: a "geração claridosa".

Por outro lado, o fragmento selecionado apresenta a mulher chefe-de-família, situação comum em Cabo Verde em vista da taxa altíssima de emigração masculina e à maternidade precoce. Estes fatores, conjugados, ensejam famílias com grande número de filhos sustentados por mulher e a pecuária familiar é uma das garantias de sobrevivência da família rural mantida pela mãe que carrega água, trabalha na frente de abertura de estradas e nos transporte de cargas, leva horas para acender o fogão tradicional de três pedras. Essa mulher será retratada em inúmeras crônicas.

Em "Cinza", Fátima pinta o povo cabo-verdiano, em painel composto sobretudo por mulheres, com paisagem típica do cotidiano crioulo ao fundo:

"O mercado, uma beleza para os olhos. O colorido de mãos dadas com a abundância, nem sei como, num ano crã como este. (...) das ribeiras e hortinhas perdidas nos vales recônditos saíram os rubros tomates, o feijão verde, o pimentão estuante de brilho e cor, o milho em todas as suas formas, reduzido a farinha, a xerém e a rolom, o côco, a mandioca, a batata, a couve, os temperos verdes fresquinhos, muita cebola verde e coentros e salsas, um cheirinho bom de terra molhada e fértil subindo até às narinas (...).

O cenário assemelha-se a uma aguarela, a beleza é de tirar o fôlego. Vida é isso aí, o povo autêntico e real em toda a sua nobreza e pujança despido de sofisticação, as mulheres aconchegando o corpo com os panos de obra vão tentendo o milho ao compasso dos fartos seios, renovando as dunas de farinha, de rolão, de xerém, expostas sobre as bancas e em permanente trânsito para o saco das compradoras (...,) rindo-se contentes as duas, a vendedeira e a freguesa" (Ibidem, pp. 33-34, grifos nossos).

Ressalte-se que o milho, alimento fundamental à culinária identitária e símbolo cabo-verdiano (que consta da bandeira do país) será, assim como no fragmento acima, várias vezes referido, por sua importância, pelo texto de Fátima Bettencourt. 
Na crônica "Pobreza", a miséria, assim como a beleza (vide crônica anterior), tem rosto de mulher: "(...) a triste imagem duma mulher de mão no queixo, desanimada, frente ao lume apagado e à panela vazia" (Ibidem, p. 179).

Os fatores concorrentes para a pobreza serão relacionados pela cronista:

"o passado histórico, a insularidade, o clima, a seca. Estes, infelizmente, são factores difíceis de manejar pela impossibilidade óbvia de, o homem caboverdiano, por mais inventivo que seja, não ser capaz de alterar qualquer deles" (Ibidem, p. 180).

O dilema hamletiano seca $\mathrm{x}$ chuva será discutido por Fátima, mormente na crônica "Chuvas":

"O certo é que quando já não se esperava, caíram as benditas chuvas, não sei se igualmente por todo o país, mas pelo menos nas ilhas mais produtivas.

Enquanto 'esverdinham-se os montes', uma nova esperança aparece no olhar dos camponeses, das vendedeiras do mercado (...) vai continuar por algum tempo ainda, mas valha-nos a certeza que vem ao feijão verde, abóbora, hortaliças muitas, mesmo que para o milho esta chuva seja por demais tardia. A acreditar em Baltasar Lopes, chuva que não produz milho não é digna do honroso título de boas as-águas o que não impede que o sentimento geral seja apenas de gratidão.

A nossa cidade é que, nitidamente, não foi feita para chuvas que rapidamente se transformam em caudais de lama e lixo, galgam pontes e acabam no mar não sem antes deixarem atrás de si charcos, lagoas e pântanos. Os mais deserdados, esses sentem na pele e nas paredes dos periclitantes lares o acerto de um dos nossos portas ao afirmar: 'si ca tem tchuba, morrê di sede/si tchuba bem, morrê fogado' (...).

Esta é a triste sina destas ilhas, sina que nos leva a, com uma mão, pedir a Deus as benditas gotas e com a outra acender uma vela a santa Bárbara que lá nas nuvens é a soberana dos temporais" (Ibidem, p. 549-550).

O fragmento dialoga evidentemente com um dos mais famosos romances sobre o binômio seca-chuva e um dos textos mais reescritos e discutidos pela literatura cabo-verdiana: Flagelados do vento leste, de Manuel Lopes, que confron- 
ta a esperança da chuva ante ao contexto de desolação da seca e, ao mesmo tempo, a violência dos temporais trazidos pelo vento harmatão.

As citações literárias, reiteradas, permitem que o leitor perceba o trabalho intertextual que Fátima Bettencourt opera, sobretudo, com obras fundadoras da literatura crioula, escrita e oral (de Baltasar Lopes, Manuel Lopes, Eugénio Tavares ou Nhô Eugénio, pp. 469-471, e B. Léza, p. 329), num constante reinventar da tradição, linha tão cara à produção ficcional da autora. Teixeira de Sousa, Sérgio Frusoni, grande cultor do crioulo literário (p. 180), Yolanda Morazzo (p. 118) são importantes escritores da série literária crioula chamados à sua "conversa-puxa-conversa" (p. 109), assim como a ficcionista Orlanda Amarílis (p. 87) e escritores contemporâneos como Germano de Almeida (p. 243), Corsino Fortes (pp. 118, 119 e 470), Dina Salústio (pp. 146-147), Vera Duarte (pp. 105, 348 e 441), Mário Lúcio (p. 106), pintores (como Kiki Lima, pp. 235-7) e cineastas (como Leão Lopes, p. 537). Também estudiosos da literatura cabo-verdiana, como Michel Laban (p. 79) e Simone Caputo Gomes (pp. 105-7) são convocados pelo texto de Fátima Bettencourt, no propósito de elaborar um painel de e sobre Cabo Verde.

A fome e a(o) cólera, flagelos crioulos, são apresentados na crônicas "Dívida, fome e moléstia", "Quem dá o que não tem..." e "Cidade atônita". Observemos:

"Lembrei-me então de um velhote de Santo Antão que dizia há muitos anos que lema de pobre era 'dívida, fome e moléstia'. (...) Dizia que quando o pobre já não tinha nenhum rendimento, ainda lhe sobejava o crédito que granjeara em melhores dias. Ora crédito tem limite e um limite curtíssimo quando não se amortiza. Aí o pobre passa também a caloteiro. Perdidos os recursos e o crédito vem a fome que por sua vez reveste-se de duas formas: a envergonhada que fica num canto até definhar e morrer e a declarada que enfileira à porta das igrejas, invade ruas e portões e às vezes, como aconteceu no passado, assalta armazéns e lojas. De qualquer forma fome sem remédio e logo, logo, as doenças e a morte, (...) vindo os mais desnutridos a ser agora pasto da cólera" (Ibidem. "Dívida, fome e moléstia", 252-252).

"Deita-se o herói, estende o braço e lá começa a operação de passar a vida da veia de um para a de outro. No segundo decilitro, porém... mas... o que é isso... o 
que está acontecendo? O homem está por demais pálido e suando frio, começa a revirar os olhos e... pimba! Desmaia sem dar tempo para nada. (...)

E um engraçadinho que assistia à cena sai-se com esta tirada de humor negro: 'Este parece mais um 'da dor' de fome do que um doador de sangue” (Ibidem. "Quem dá o que não tem...”, p. 489, grifos nossos).

"O meu regresso a Mindelo coincidiu com a chegada da cólera (...) o cidadão comum parecia atônito e incrédulo face às primeiras notícias; (...) o mindelense não sabe se festeja a chuva ou se lamenta a cólera" (Ibidem. "Cidade atônita", p. 262).

A crônica "De Mindelo com amor", retomando a ambiência, retrata, com a coloquialidade de uma conversa amável, as vivências crioulas da cronista, os sentimentos que a cidade, a ilha e sua gente nela despertaram:

"Mindelo vai a pouco e pouco tornando-se um estado de espírito. Baixa uma paz sobre mim quando piso este chão e ando pelas ruas, parando metro a metro, para um abraço, uma conversa amável, às vezes um alô apenas. É a minha cidade que me abre os braços e o coração e me sinto no colo mesmo da minha mãe, acalentada e confortada, em perfeita comunhão com todos e comigo mesma.

Filha adoptiva, é como se tivesse dado coices nas suas entranhas, tenho uma dívida impagável para com esta cidade, esta ilha, estes montes pelados, esta gente indómita. Eu sei que ela está paradona, estagnada, morta, mas as suas tardes continuam cálidas, as suas noites plenas de magia, e aquele toque de morabeza permanece intacto nas suas gentes que, às vezes, se levantam sem saber se verão o sol baixar no Monte Cara antes de porem uma panela de-riba-de-lume. O cati-cati de cada dia, sempre difícil, mas não a ponto de perderem o riso bom, o requebro do andar, a piada inesperada, o dito picante, a graça infinita. (...)

Bela amante adormecida(...) Quem semeará teus bairros de lares-oficinas, escolasempresas e abrigará teus velhos, teus loucos, teus meninos sózinhos, teus artistas, tuas prostitutas ainda com a boneca escondida no travesseiro?' (Ibidem, pp. 49-50. Grifos nossos).

A cidade dos músicos e poetas, berço da revista Claridade, primeira manifestação literária de uma inscrição da arte em solo crioulo, será cantada com "amor": 
"Desse amor, meu e dos outros, vive a cidade. Por isso é bonita, graciosa, hospitaleira. Por isso sua gente é amável, alegre e solidária. Por isso é a musa inspiradora de poetas e artistas" (Ibidem, p. 564).

As cantadeiras de mornas, Cesária Évora e Celina Pereira, serão celebradas na crônica "Noite de Mindelo":

"Apesar da violência crescente da cidade, a noite do Mindelo é das coisas que mais me fascina. (...)

Essa porém era uma noite especial. Chico serra, Tola's, Cise e mais uma grupo de amigos queriam fazer uma morabeza à Celina Pereira. (...)

Tocando por gosto, Chico e Tola's ultrapassaram-se.A sala foi-se enchendo aos poucos (...) nenhum resistiu ao apelo daquela música, da voz boémia da Cesária, da própria Celina em noite de glória” (Ibidem, p. 43).

Cesária é bastante conhecida como a mais famosa cantora de mornas (tipo de canção crioula identitária) do mundo; Celina alia o trabalho de recolha dos contos orais à música típica cabo-verdiana.

A cronista reproduz, em concomitância com as representações da cultura tradicional oral (os velhos, o embondeiro, a morna cantada por Cesária), a "inserção na economia mundial" (p. 90), representada pelo "Teleolhar" (nome de crônica, p. 125), pela invasão de Cabo Verde pelos micros (p. 291), discos ("o CD Room do meu computador (...) vomitando música”, pp. 293-294), pelas “assustadoras seqüelas da informática" (crônica "País real, país virtual, p. 541). As cidades cabo-verdianas e os velhos, guardiões da cultura, tentam resistir à globalização que insiste em desfigurar as suas faces:

'Uma zona histórica com seus sobrados, varandas de ferro, casinhas de meia-porta onde velhas de cachimbo se sentam para contar estórias aos netos impacientes na hora da televisão que os acaba levando, deixando a velha sozinha a derramar o seu olhar mortiço sobre as agressões que sofre a sua morada .(...) A cidade cresceu, vive apressada, não repara em nada, passa voando (...)” (“Cidade”. Ibidem, p. 365).

Apesar do trágico da cena, a advertência crítica que dirige o olhar para a importância da manutenção da cultura ainda permite esperança e utopia: 
“não vou mais encolher-me para não roçar a mão estendida do mendigo; não vou evitar o boteco da esquina onde corpos gentis de adolescentes se leiloam; não vou enjoar-me com o cheiro de 'erva' que inunda um recanto mal iluminado; não vou ver as ruas ficando desertas, as pessoas com medo de passear na Marginal nas noites quentes, os velhos parados olhando o mar, os jovens à toa, de braços caídos, a desesperança e o tédio cercando a ilha.

Aí sim, vai ser bom pisar teu chão." (“De Mindelo com amor”. Ibidem, pp. 50-51).

Tão importantes quanto Velho Embondeiro, seu símbolo, os guardiães da tradição e os seus descendentes tentam preservam a culinária das ilhas, outra marca da identidade crioula:

"Foi com enorme alegria que presenciei o (...) trabalho que a Paula Cristina vem desenvolvendo no registo das tradições e casos típicos da Ilha de Santo Antão. (...)

Rebuscando receitas originais antigas, vasculhando papéis e memórias envelhecidas mas ainda muito nítidas e desenterrando segredos ciosamente guardados pelas velhas senhoras da Ilha de Santo Antão, a Paula conseguiu recriar sabores e temperos, gestos e medidas considerados já perdidos para sempre" (Ibidem. 302).

Como é possível perceber, Fátima Bettencourt, em sua hermenêutica do cotidiano crioulo realizada pela crônica, elege como focos privilegiados o povo cabo-verdiano e, em close up, a mulher simples, compondo, por meio das "estórias dessas vivências", um "mosaico rico e colorido, pleno de vida e de calor" (Ibidem, p. 58) que compila retalhos do dia-a-dia do cabo-verdiano anônimo:

"O povo destas ilhas tem levado a cada cantinho deste planeta, o seu toque de criatividade, a marca do engenho nascido da sua vivência em condições quase impossíveis, a sua malícia e graça também frutos duma vida inteira em equilíbrio precário entre a desistência e a teimosia (...) nunca desiste de passar aos outros a sua vivência crioula, o seu grogue, o seu tabaco puído, a sua cachupa, o seu violão, a sua língua” (Ibidem, p. 58). 
Os quadros pintados por Fátima, por "Atalhos, veredas, caminhos de cabra" (título de crônica), possibilitam ao leitor, como disse José Saramago (Caboverdiando, crônica, 1998), "ver a terra e conhecer as pessoas, tremer de comoção real. Cabo Verde fabrica o seu próprio chão, inventa a sua própria água, repete dia a dia a criação do mundo. Porém, se uma simples pessoa não cabe numa crónica, como caberiam um povo e um país?

Voltando à reflexão inicial, concluímos que a tenda, cigana como o tempo "que se escoa na ampulheta da vida" (p. 54), tornou-se casa. E a casa caboverdiana segue ganhando mundo.

A lição de crônica que Fátima Bettencourt nos oferece neste volume, o seu amor ao examinar o cotidiano cabo-verdiano e o "toque crioulo", certamente não cabem em nosso texto. Vão muito além, ao encontro do leitor, no espaço mágico da comunicação.

\section{Referências bibliográficas:}

BETTENCOURT, Fátima. Um certo olhar: crônicas. Praia: Instituto da Biblioteca Nacional-Direcção do Livro, 2001.

BETTENCOURT, Fátima. Semear em pó. Praia: Instituto Caboverdiano do Livro e do Disco, 1994.

BETTENCOURT, Fátima. "Angústia” (crônica). Praia. Jornal A semana. Maio de 1992, cedida pela autora.

SÁ, Jorge de. A crônica. São Paulo: Ática, 1985. Série Princípios.

SARAMAGO, José. Caboverdiando, crônica. Jornal de Letras. Lisboa, 731: 28-29, 14 de outubro de 1998. 